\title{
Impacts of Workplace Stress: An Exploratory Cross-Sectional Study of Oil and Gas Sector in Pakistan
}

\begin{abstract}
Aftab Ahmad ${ }^{1,2}$, Mudasrah Rahman ${ }^{2}$, Shagufta Yasmin ${ }^{3}$, Nasif Raza Jaffri ${ }^{4}$, Usama Abrar ${ }^{4}$, Saad Aslam ${ }^{2}$

Abstract

Working eternally from the shoreline is all around considered as a distressing profession where work environment stress is accepted as a noteworthy danger aspect for mental ailment. Then again, stress-related substance relating to this part is scant. The aim of present research is to investigating the components of impacts of work-stress among the individuals working offshore in managerial cadres of oil and gas sector organizations at Pakistan. A self-designed instrument was used to gather information for this cross-sectional examination. Measure's legitimacy was built up by ascertaining Cronbach's alpha (0.914). Exploratory factor analysis (EFA) with Principal Component Analysis extraction method and Oblimin with Kaiser Normalization rotation method was applied on the collected information. Bartlett's test of sphericity and the Kaiser-Meyer-Olkin (KMO) proved the suitability of the collected data for exploratory factor analysis. EFA distinguished four components for the impacts of work-stress: Psychological; Performance; physiological, and Cognitive. These components explained $73.62 \%$ of total variance. The component Psychological was the most noteworthy component. This investigation has not just recognized the significant impact components of work-stress in seaward oil organizations at Pakistan yet in addition gave an organized rundown of these components. Discoveries of the investigation will support analysts, employers, bosses and the specialists to devise and execute pressure avoidance and development technique. This is the ever first work of its sort in Pakistan.
\end{abstract}

Keywords: Oil and gas sector, offshore, consequences of work-stress, impacts, exploratory factor analysis.

\section{Introduction}

The concept of occupational stress has a complex nature. It is also known as job stress. It is a negative mental experience coming about as a result of stressors at the work environment (Stellman, 1998) and a diverse, multi-dimensional lively process where

${ }^{1}$ Department of Electrical Engineering, NFC Institute of Engineering and Fertilizers Research (NFC-IEFR), Faisalabad, Pakistan

${ }^{2}$ Department of Industrial and Manufacturing Engineering, University of Engineering and Technology (UET), Lahore, Pakistan

${ }^{3}$ School of Social Sciences and Humanities, University of Management and Technology (UMT), Lahore, Pakistan

${ }^{4}$ School of Control and Computer Engineering, North China Electric Power University Beijing, 102206 China

Corresponding Author: aftabahmadrao@gmail.com 
Aftab Ahmad et al. Impacts of Workplace Stress: An Exploratory Cross-Sectional Study of Oil and Gas Sector in Pakistan (pp. 70-79)

reasons of stress and occurrence of stress might happen right away or somewhat else. It results in psychosomatic and physiological issues (Stellman, 1998), for instance, cardiovascular disorders (Theorell \& Karasek, 1996), mental disarranges (Stellman, 1998; Fingret, 2000), musculoskeletal misery (Carayon, Smith, \& Haims, 1999) and gastrointestinal dissipates (Levenstein, 2000). Be that as it may, the impacts might be limited by the other psychosocial factors, for instance, people's handling advances (Stellman, 1998).

In earlier multiple examinations, working environment stress has been set up as a critical perilous factor for psychic unsteadiness amongst the people in a broad extent of occupations. It may not just influence the execution and effectualness of the people yet in addition negatively influence them physically, psychologically, and behaviorally (Ahmad, Hussain, Mughal, Mufti, \& Saleem, 2019). A longitudinal survey in the UK uncovered that, during 1996-2001 and on an average, yearly 3642 new cases of employment related mental infirmity were recognized, and most by far of them were a result of occupation related pressure (Cherry, Chen, \& McDonald, 2006). A study on the textile industry found $48 \%$ of the managers in higher stress levels (Ahmad, Hussain, Mughal, Mufti, \& Saleem, 2018) while the investigation performed on the overall employees of the sector disclosed 61\% in higher levels of stress (Ahmad, Hussain, Mughal, Mufti, Saleem, \& Ahram, 2020b). Dozing issues, weariness, troubles in separating from work (Mette, Velasco, \& Harth, 2018a; Chung, Lee, \& Lee, 2017), diminutive drive, diminished execution, job uncertainty, absence, work-life contradiction, wellbeing issue, and quickened turnover are the hostile effects of workplace stress(Babatunde, 2013). It has been found that psychological stress damage employees' work execution, team execution, working relationship, joint effort among associates, and team strength (Islam, Muhajan, \& Datta, 2012). Working in oil and gas fields is comprehensively seen as a trouble calling, and the people utilized in this occupation are accessible to both the stressors of general nature and those particular to the offshore workplace (Sutherland \& Cooper, 1989; Parkes, 1998). Considering this background, this cross-sectional assessment is planned for investigating the impact components of workplace stress among the employees working in management cadre of oil and gas division of Pakistan.

Working environment stress is a universal phenomenon that adversely affects not only the physical health, psychological health and behaviors but also performance of the employees of any organization. An extensive research of the literature supports the relationship between workplace factors, stress and their impacts. Impacts of stress are different for different human beings because the perception of humans about stress is also different. Workplace stress is an open challenge to the proper working of organizations and employees. The rationale behind the present study is to explore the impact components of the workplace stress among the individuals working eternally from the shoreline and the study is exploratory up to the extent of Pakistani offshore oil and gas sector. 
Aftab Ahmad et al. Impacts of Workplace Stress: An Exploratory Cross-Sectional Study of Oil and Gas Sector in Pakistan

\section{Literature Review}

Numerous studies have so far been carried on the stress related affairs. It may be measuring perceived stress, identifying causes, exploring effects of work-stress, or finding out stress preventing and controling interventions. Howerve, lesser stress has been found in exploring or identifying the consequences of work-stress as compared to exploring the stressors. $\mathrm{Li}$, Chen, $\mathrm{Wu}$, and Sung (2001) found a positive correlation between work stress and workplace injuries. Shahid, Latif, Sohail, and Ashraf (2011) studied the stress related problem of bankers and explored that stress contribute to decline organizational performance, diminished employee overall performance, decreased quality of work, high staff turnover and absenteeism, augmented health problems such as anxiety, depression, headache and backache. Islam, Muhajan, and Datta (2012) showed that stress reduces employee work performance, team performance, team spirit, working relationship, cooperation between team members, however, impact depends on the individual's strength, personality, environment or situation and adoption process. Shikieri and Musa (2012) determined the factors related to occupational stress and their correlation with organizational performance in a private university of Sudan. The results showed that job stress impacts organizational accomplishments by dropping efficiency and eventually productivity. Ahmad and Ramzan (2013) concluded that occupational stress considerably decreases the performance of individuals. According to Kotteeswari and Sharief (2014) stress factors affect the performance of employees in a negative way. Banoand Malik (2014) investigated the impacts of occupational stressors on life satisfaction among private and government school teachers and found a negative correlation between occupational stress and life satisfaction. Barboza and Thomas (2015) identified high turnover, high absenteeism, decreased productivity, lower performance, low morale, high employee grievances and adverse physiological, behavioral, physical, Psychological, emotional effects as the consequences of stress among the employees of insurance sector. In a review of several prospective and high-quality studies, it has been concluded that severe job stress results in augmented possibility of human error and accident happening, mental health concerns, increased turnover in organizations, adverse physical, psychological and occupational consequences; starting with depression and anxiety, passed on to maladaptive behaviors, and ending in job burnout (Salvagioni, Melanda, Mesas, González, Gabani, \& de Andrade, 2017; Giorgi, et al., 2017; Petrie, Crawford, Shand, \& Harvey, 2020; Kerdpitak \& Jermsittiparsert, 2020; Darling \& Whitty, 2019; Richardsen, Martinussen, \& Kaiser, 2019).

Number of studies has been conducted on stress related matters in general. Yet, such studies in relation to the individuals working offshore are limited. According to Cooper and Sutherland (1987), high proportion of offshore personnel has high level of nervousness. Parkes (1992) investigated the cerebral health of workforce in the oil industry and found that stress results in high level of anxiety amongst offshore workforce than amongst those functioning onshore. Parkes (1998) reviewed the stressrelated literature pertaining to offshore workers and found that offshore workers face high level of anxiety, higher amount of work, and more sleep difficulties and 
Aftab Ahmad et al. Impacts of Workplace Stress: An Exploratory Cross-Sectional Study of Oil and Gas Sector in

disturbances as compared to onshore personnel. Chen, Wong, and Yu (2008), working on the population of Chinese Off-shore oil workers, found a positive relationship between stress and "current drinking". Hystad, Saus, Saetrevik, and Eid, (2013) found physical fatigue, mental fatigue, and shortage of energy as the impacts of psychological stress among offshore oil and gas industry employees. In a study of German offshore wind industry, fatigue, difficulties detaching from work, sleeping problems; and musculoskeletal and gastrointestinal complaints were found as the consequences of stress at work (Mette, Garrido, Harth, Preisser, \& Stefanie, 2018). Despite availability of some state-of-the-art stress-related literature in the offshore sector, no such work is found for offshore oil and gas industry at Pakistan. In attempting to explore impact components of work stress, the current study is the ever first of its sort in Pakistan. Although, several studies have been conducted in Pakistan on stress-related matters yet these studies pertained to other sectors.

\section{Methodology}

\subsection{Preparation of questionnaire}

So as to achieve the object of the present research, as placed in the preceding section, an extensive literature was reviewed for the impacts of work-stress besides having observations and study related feedback from the industry. Thereupon, in exploring the impact components of work stress on the employees, a data collection instrument was developed. It was consisted of 27 items and covered the domains, namely: psychological, performance, physiological, behavioural, emotional and cognitive. In order to identify these impact components, 5-point Likert-type scale was used. Reliability of the instrument was assessed by calculating Cronbach's alpha value which was found to be very good, explicitly 0.914 . This scale ranged from 1 through 5 , where ' 1 ' indicated 'no impact' and ' 5 ' indicated 'high impact' $(1=$ strongly disagree, $2=$ disagree, $3=$ neutral, $4=$ agree, $5=$ strongly agree). Particular perspective of the study necessitated the development data collection instrument.

\subsection{Participants}

All in all, 100 participants from different positions of the management cadre participated in the survey which was conducted in the offshore oil and gas companies at Pakistan. All the participants were male employees as no female employee is assigned to perform offshore duties in Pakistan. They were comprised of country directors, drilling engineers and senior drilling engineers.

\subsection{Analysis}

So as to reach the objective of the study, EFA (exploratory factor analysis) with PCA (principal component analysis) as extraction method and Oblimin with Kaiser Normalization as rotation method was applied on the collected information. EFA was used to explore the underlying theoretical structure of the phenomena, that is, to find the impact components of workplace stress. Prior to the deployment of EFA on the data collected, suitability of the data for EFA was assessed through the Bartlett's test of sphericity and the Kaiser-Meyer-Olkin (KMO) measure of sampling adequacy. 
Aftab Ahmad et al. Impacts of Workplace Stress: An Exploratory Cross-Sectional Study of Oil and Gas Sector in Pakistan

\section{Results and Discussion}

\subsection{Bartlett's test of sphericity and the KMO measure of sampling adequacy for impacts of stress}

In order to compute the final results, suitability of the data for factor analysis was checked. It was determined by using the Bartlett's test of sphericity and the KMO measure of sampling adequacy. Results of the test are shown in the Table 1 . The value of KMO test came out to be 0.722 which is an acceptable value (Kaiser, 1974). The same table shows the significance of Bartlett's test of sphericity as 0.000 (this value is less than the required value of 0.05 (Bartlett, 1954)).

Table 1: Kaiser-Meyer-Olkin Measure of Sampling Adequacy

\begin{tabular}{|l|l|r|}
\hline \multicolumn{2}{|l}{ KMO and Bartlett's Test } \\
\hline Kaiser-Meyer-Olkin Measure of Sampling Adequacy. & .722 \\
\hline \multirow{3}{*}{ Bartlett's Test of Sphericity } & Approx. Chi-Square & 1932.368 \\
\cline { 2 - 3 } & df & 351 \\
\cline { 2 - 3 } & Sig. & .000 \\
\hline
\end{tabular}

\subsection{Exploratory factor analysis of impacts}

Exploratory factor analysis was applied to explore the impact components of workstress among the employees of offshore companies at Pakistan. Table 2 shows the results of the analysis. It is evident that 4 components were identified after the application of EFA using PCA as extraction method and Oblimin with Kaiser Normalization as rotation method. Extraction of the components was done on the basis of the scree plot criterion (Cattell, 1978). Figure 1 shows that four components are above the point of inflexion. The components before the point of inflexion are considered to be the most critical components because they explain a larger value of the total variance. All in all, 14 items loaded onto these four components. Majority of the items are loaded heavily $(>.80)$ onto their respective components. Hence, the study sample size is proved to be in accordance with the guidelines of Guadagnoli and Velicer (1988) where they suggested that if the dataset has a number of high factors loading scores $(>.80)$, then a lesser small size $(n>150)$ should be sufficient. Items below 0.6 loading value are suppressed deliberately. These components have been explained in the following subsections.

\subsubsection{Component 1: Psychological}

Five items loaded onto this component and loaded intensely. The item 'I have had trouble paying attention' (0.907) emerged more vigorously. I often experience confusion' (0.884) and 'I experience difficulty in making decisions' (0.829) also emerged vigorously. Fourth loaded item is 'My concentration and memory is impaired' (0.746) whereas the fifth is 'I have difficulty with thought process' with loading value of 0.689. All the items belong to the psychological impacts on the individuals; therefore, this factor is named as psychological. The component is the most critical component as it explains $37.85 \%$ of the total variance, Table 2 . 


\subsubsection{Component 2: Performance}

Three items are loaded onto this component and loaded heavily. It is the second most critical component and explains $15.03 \%$ of the total variance. First loaded item is ' $I$ experience time management issues' with loading value of 0.874 . The second loaded item is 'I am unable to complete the task as per schedule' $(0.817)$ while the third is ' $I$ feel that deadlines are difficult to meet in my work' (0.781). All these items belong to the individuals' performance in executing their assigned jobs; therefore, this factor is named as performance.

\subsubsection{Component 3: Physiological}

This component consists of three items. All the items loaded heavily onto the component. These items are 'I have headaches'; 'I feel myself trembling'; and 'I lack physical energy' with loading values $0.883,0.778$ and 0.660 respectively. All the items loaded onto this component belong to the physiological effects on the individuals; therefore, the component is named as physiological. The component explains $12.27 \%$ of the total variance.

\subsubsection{Component 4: Cognitive}

This component also consists of three items. These items are 'I am unable to utilize all the resources', My judgment is not good', and 'I am ineffective in resolving family issues' with loading values $0.829,0.807$, and 0.726 respectively. All the items loaded onto this component belong to the cognitive ability of the individuals; therefore, the component is named as Cognitive. The component explains $8.48 \%$ of the total variance.

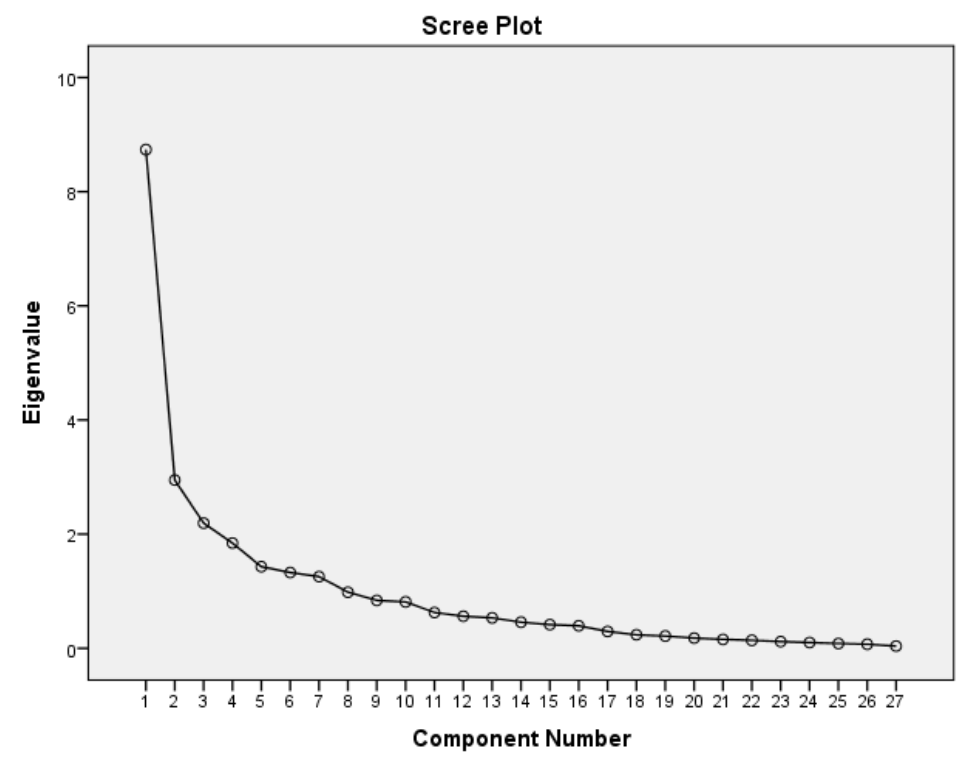

Figure 2: Scree Plot 
Aftab Ahmad et al. Impacts of Workplace Stress: An Exploratory Cross-Sectional Study of Oil and Gas Sector in Pakistan

\subsection{Reliability of components}

The results placed in Table 2 also show the Cronbach alpha coefficient for all of these components that emerged for the impacts of stress. According to these results, all the components have reliability coefficients i.e. Cronbach alpha greater than 0.7 which is quite acceptable.

\subsection{Inter-factor correlation of components}

Table 3 explains the correlation among the extracted components. It is evident that each component is explaining a construct which is different from the others as the correlation values are much lesser than 0.5. The correlation matrix placed in Table 3 is just to demonstrate the distinctiveness of the components.

Table 3: Component Correlation Matrix

\begin{tabular}{|c|c|c|c|c|}
\hline Component & 1 & 2 & 3 & 4 \\
\hline 1 & 1.000 & & & \\
\hline 2 & .250 & 1.000 & & \\
\hline 3 & .143 & .130 & 1.000 & \\
\hline 4 & .447 & .124 & .113 & 1.000 \\
\hline
\end{tabular}

\subsection{Comparison with other studies}

The study aimed at exploring impacts of work-stress among the individuals working in management cadre of offshore oil and gas companies at Pakistan. This investigation has not just recognized the significant components for the impacts of work-stress in seaward oil organizations at Pakistan yet in addition gave an organized rundown of these components. The present study revealed four stress impact components, namely: psychological, performance, physiological, and cognitive. Simply it is found that the work-stress has potential adverse impacts on the employees' psychological conditions, performance, physiology, and cognitive ability. Mette et al. (2018), in their work on offshore wind industry, found fatigue, musculoskeletal and gastrointestinal problems as the consequences of stress at work. These impacts belong to the component physiological impacts; found in the current study as stress impact component. Our finding, up to the extent of physiological impacts, is also consistent with the earlier research done on the individuals working in offshore oil and gas sector at Norway (Riethmeister, Brouwer, van der Klink, \& Bültma, 2016) and also those relating to the seafaring branch (Hystad, Saus, Saetrevik, \& Eid, 2013) besides the results of work done by Bjerkan (2011) in comparing onshore and offshore employees of Norwegian oil companies. The impact lack of energy, found by Hystad et al. (2013), correspond to the item I lack physical energy found in our study in component physiological. In contrast to dissimilar outcomes concerning offshore and onshore workers' 
Aftab Ahmad et al. Impacts of Workplace Stress: An Exploratory Cross-Sectional Study of Oil and Gas Sector in Pakistan

psychological healthiness (Parkes, 2002; Berthelsen, Pallesen, Bjorvatn, \& Knardahl, 2015; Parkes, 1998), symptoms of anxiety or depression were not found in our study.

\section{Conclusion}

The study identified the impact components of work-stress amongst the management cadre offshore employees of oil and gas sector in Pakistan. Exploratory factor analysis (EFA) was deployed on the information gathered in a cross-sectional examination. Four components indicating impacts of work-stress have been identified. The components are psychological, performance, psychological, and cognitive. The component psychological is the most critical component. Interventions by the organizations are indispensable to turn the corner. More research is obligatory to take a broad view on the outcomes of this study and to institute a consistent demonstration of work-stress impacts on the individuals working offshore. For upcoming explorations, it is suggested that quantitative research works with larger study samples be carried out to explore the actual impact of work-stress on the offshore employees.

\section{Author Contribution}

Aftab Ahmad: Conceptualization, Methodology, Data Analysis, Writing-Final draft preparation

Mudasrah Rahman: Data Collection, Writing- Original draft preparation.

Shagufta Yasmin: Data Collection, Writing- Reviewing and Editing

Nasif Raza Jaffri: Writing- Review, Supervision

Usama Abrar: Data Collection, Software-Data Analysis,

Saad Aslam: Data Collection, Writing- Reviewing and Editing

\section{DATA AVAILABILTY STATEMENT}

The datasets generated during and/or analyzed during the current study are available from the corresponding author on reasonable request.

\section{CONFLICT OF INTEREST}

No conflict of interest

\section{FUNDING}

No funding is received for this research project

\section{REFERENCES}

Ahmad, A., \& Ramzan, M. (2013). Effects of Job Stress on Employees Job Performance: A Study on Banking Sector of Pakistan. IOSR Journal of Business and Management , 6168.

Ahmad, A., Hussain, A., Mughal, M. P., Mufti, N. A., \& Saleem, M. Q. (2019). Effects of Workplace Stress on Managers of Textile Industries of Developing Countries: A Case Study from Pakistan. In J. Kantola, S. Nazir, \& T. Barath (Eds.), Advances in Intelligent 
Aftab Ahmad et al. Impacts of Workplace Stress: An Exploratory Cross-Sectional Study of Oil and Gas Sector in

Systems and Computing (Advances in Human Factors, Business Management and Society ed., Vol. 783, pp. 500-507). Springer, Cham.

Ahmad, A., Hussain, A., Mughal, M. P., Mufti, N. A., \& Saleem, M. Q. (2018). Workplace Stress Assessment Among Managers of Textile Industries at Developing Countries: A Case Study from Pakistan. In Advances in Human Factors, Business Management and Leadership, AHFE 2017 (Vol. 594, pp. 382-391). Cham: Springer.

Ahmad, A., Hussain, A., Mughal, M. P., Mufti, N. A., Saleem, M. Q., \& Ahram, T. (2020b). Perceived stress: levels and role of demographics - a cross-sectional study of textile industry employees. Industria Textila, 71 (2), 180-185.

Babatunde, A. (2013). Occupational Stress: A Review on Conceptualisations, Causes and Cure. Economic Insights - Trends and Challenges, II (LXV) (3), 73-80.

Bano, S., \& Malik, S. (2014). Effect of Occupational Stress on Life Satisfaction among Private. Journal of Independent Studies and Research-Management, Social Sciences and Economics, 12.

Barboza, C., \& Thomas, B. (2015). Impact of Stress on Productivity of Employees in Insurance Sector - Dakshina. International Journal in Management and Social Science , 428-437.

Bartlett, M. S. (1954). A note on the multiplying factors for various chi square approximations. Journal of Royal Statistical Society, 16 (Series B), 296-298.

Berthelsen, M., Pallesen, S., Bjorvatn, B., \& Knardahl, S. (2015). Shift schedules, work factors, and mental health among onshore and offshore workers in the Norwegian petroleum industry. Industrial Health, 53, 280-292.

Bjerkan, A. M. (2011). Work and health: a comparison between Norwegian onshore and offshore employees. Work, 40 (2), 125-42.

Carayon, P., Smith, M. J., \& Haims, M. C. (1999). Work organization, job stress, and workrelated musculoskeletal disorders. Human Factors, 41 (4), 644-663.

Cattell, R. B. (1978). The scientific use of factor analysis inbehavioral and life sciences. New York, NY: Plenum Press.

Chen, W. Q., Wong, T. W., \& Yu, I. T.-S. (2008). Wei Qing Chen, Tze Wai Wong, and Ignatius Tak-Sun Yu, Association of Occupational Stress and Social Support with Health related Behaviors among Chinese Offshore Oil Workers. Journal of Occupational Health, 50, 262-269.

Cherry, N. M., Chen, Y., \& McDonald, J. C. (2006). Reported incidence and precipitating factors of work-related stress and mental ill-health in the United Kingdom (1996-2001). Occupational Medicine, 56 (6), 414-421.

Chung, Y.-S., Lee, P. T.-W., \& Lee, J.-K. (2017). Burnout in seafarers: its antecedents and effects on incidents at sea. Maritime Policy \& Management, 44 (7), 916-931.

Cooper, C. L., \& Sutherland, V. J. (1987). Job stress, mental health, and accidents among offshore workers in the oil and gas extraction industries. Journal of Occupational Medicine, 29, 119-125.

Fingret, A. (2000). Occupational mental health: a brief history. Occupational Medicine, 50 (5), 289-293.

Giorgi, G., Arcangeli, G., Perminiene, M., Lorini, C., Ariza-Montes, A., Fiz-Perez, J., et al. (2017). Work-Related Stress in the Banking Sector: A Review of Incidence, Correlated Factors, and Major Consequences. Frontiers in Psychology, 8, 2166.

Guadagnoli, E., \& Velicer, W. F. (1988). Relation to sample size to the stability of component patterns. Psychological Bulletin, 103 (2), 265-275.

Hystad, S. W., Saus, E.-R., Saetrevik, B., \& Eid, J. (2013). Fatigue in seafarers working in the offshore oil and gas re-supply industry: effects of safety climate, psychosocial work environment and shift arrangement. International Maritime Health, 64 (2), 72-9. 
Aftab Ahmad et al. Impacts of Workplace Stress: An Exploratory Cross-Sectional Study of Oil and Gas Sector in

Islam, J. N., Muhajan, H. K., \& Datta, R. (2012). Stress Management Policy Analysis: A preventive approach. International Journal of Economics and Research, 01-17.

Kaiser, H. F. (1974). An index of factorial simplicity. Psychometrica, 39 (31-36).

Kotteeswari, M., \& Sharief, S. T. (2014). Job Stress and Its Impact on Employees' Performance: A Study with Reference to Employees Working in BPOS. International Journal of Advanced Research in Management (IJARM), 5 (2), 19-27.

Levenstein, S. (2000). The Very Model of a Modern Etiology: A Biopsychosocial View of Peptic Ulcer. Psychosomatic Medicine, 62 (2), 176-185.

Li, C. Y., Chen, K. R., Wu, C. H., \& Sung, F. C. (2001). Job stress and dissatisfaction in association with non-fatal injuries on the job in a cross-sectional sample of petrochemical workers. Society of Occupational Medicine, 51 (1), 50-55.

Mette, J., Garrido, M. V., Harth, V., Preisser, A. M., \& Stefanie, M. (2018). Healthy offshore workforce? A qualitative study on offshore wind employees' occupational strain, health, and coping. BMC Public Health, 18 (172).

Mette, J., Velasco, M. G., \& Harth, V. (2018a). Healthy offshore workforce? A qualitative study on offshore wind employees' occupational strain, health, and coping. BMC Public Health, 18, 172.

Parkes, K. R. (1992). Mental health in oil industry: A comparative study of onshore and offshore employees. Psychological Medicine, 22, 997-1009.

Parkes, K. R. (1998). Psychosocial aspects of stress, health and safety on North Sea installation. Scandinavian Journal of Work, Environment \& Health, 24, 321-333.

Parkes, K. R. (2002). Psychosocial aspects of work and health in the North Sea oil and gas industry. University of Oxford for the Health and Safety Executive, Sudbury.

Riethmeister, V., Brouwer, S., van der Klink, J., \& Bültma, U. (2016). Work, eat and sleep: towards a healthy ageing at work program offshore. BMC Public Health, 16 (1), 134.

Salvagioni, D. A., Melanda, F. N., Mesas, A. E., González, A. D., Gabani, F. L., \& de Andrade, S. M. (2017). Physical, psychological and occupational consequences of job burnout: A systematic review of prospective studies. PLoS ONE, 12 (10), Article e0185781.

Shahid, M. N., Latif, K., Sohail, N., \& Ashraf, M. A. (2011). Work stress and employee performance in banking sector, Evidence from District Faisalabad, Pakistan. Asian Journal of Business and Management Sciences, 1, 38-47.

Shikieri, A. B., \& Musa, H. A. (2012). Factors associated with Occupational Stress and Their Effects on organizational performance in a Sudanese Universities. Creative Education, 3 (SciRes), 134-144.

Stellman, J. (1998). Encyclopedia of Occupational Health and Safety (4th ed.). Geneva: ILO.

Sutherland, V. J., \& Cooper, C. L. (1989). Occupational stress in the offshore oil and gas industry. International Reviews of Ergonomics, 2, 183-215.

Theorell, T., \& Karasek, R. A. (1996). Current issues relating to psychosocial job strain and cardiovascular disease research. Journal of Occupational Health Psychology, 1 (1), 926. 